\title{
Los efectos en el tiempo de los cambios jurisprudenciales de las sentencias de unificación del Consejo de Estado y la Corte Constitucional de Colombia
}

\author{
The effects over time of the jurisprudential changes of the unification judgments of the \\ Council of State and the Constitutional Court of Colombia
}

César Augusto Benavidez Vega - Jorge Alberto Gaviria²

\section{Resumen}

En Colombia la adjudicación del derecho es una práctica sumamente compleja que involucra múltiples decisiones todo el tiempo: Sobre los hechos del caso, las normas jurídicas a aplicar, su interpretación, sus efectos, su concordancia con otras fuentes del ordenamiento jurídico, etc. Situación agravada por la coexistencia de tres altas cortes encargadas de unificar la jurisprudencia en sus respectivas jurisdicciones, a raíz de la diversidad de criterios de los jueces de instancia. Con tal propósito el Consejo de Estado y la Corte Constitucional cuentan con las sentencias de unificación jurisprudencial. Sin embargo, esta herramienta no está exenta de vicisitudes en su aplicación a casos concretos. En especial, cuando por la veleidad ocurren cambios jurisprudenciales respecto de las subreglas que venían siendo observadas. Esta investigación responde dos preguntas en el marco de las sentencias de unificación del Consejo de Estado y la Corte Constitucional: i) ¿Cuándo un cambio jurisprudencial es legítimo? ii) ¿Cómo se aplica la nueva subregla en el tiempo? Desde un enfoque dogmático del derecho se empleó la metodología de enfoque cualitativo, a partir de análisis documental de doctrina y jurisprudencia. Se concluyó que un cambio jurisprudencial es legítimo sí y solo sí cuando cumple con la carga de la transparencia y la carga de la argumentación. Además, si bien las sentencias de unificación son un mecanismo necesario para garantizar el derecho a la igualdad y la seguridad jurídica, estas también precisan de la modulación de sus efectos en el tiempo, pasando de la aplicación retroactiva a la prospectiva, a partir de un enfoque de derechos.

Palabras clave: Cambios jurisprudenciales; sentencias de unificación; Consejo de Estado; Corte Constitucional; retroactividad: retrospectividad; prospectividad.

\begin{abstract}
In Colombia, the adjudication of the right is an extremely complex practice that involves multiple decisions all the time: On the facts of the case, the legal norms to be applied, its interpretation, its effects, its concordance with other sources of the legal system, etc. Situation aggravated by the coexistence of three high courts in charge of unifying jurisprudence in their respective jurisdictions, as a result of the diversity of criteria of the judges of instance. To this end, the Council of State and the Constitutional Court have the judgments of jurisprudential unification. However, this tool is not without vicissitudes in its application

\footnotetext{
${ }^{1}$ Abogado de la Universidad de Antioquia (Medellín, Colombia). Estudiante de Especialización en Derecho Administrativo de la Corporación Universitaria Americana (Medellín). Tesis de pregrado distinguida con mención especial. Ganador del II Concurso de Ensayo Germán Cavelier 2018-2 (Universidad de Antioquia) de la Asociación Cavelier del Derecho. Miembro del semillero de Estudios Críticos sobre Democracia de la Facultad de Derecho y Ciencias Políticas de la Universidad de Antioquia. Miembro de la Red Internacional de Investigación sobre Democracia, Derecho y Política desde México y Colombia (Universidad Juárez del Estado de Durango y Universidad de Antioquia). Correo electrónico: cesar.benavidez@udea. edu.co. https://orcid.org/0000-0003-4523-9683
}

${ }^{2}$ Abogado de la Corporación Universitaria Americana (Medellín, Colombia). Estudiante de Especialización en Derecho Administrativo de la Corporación Universitaria Americana (Medellín). Correo electrónico: jorgegaviria1981@gmail.com 
to specific cases. In particular, when due to the vagaries there are jurisprudential changes with respect to the sub-rules that had been observed. This research answers two questions in the framework of the unification judgments of the Council of State and the Constitutional Court: i) When is a jurisprudential change legitimate? (ii) How is the new sub-rule applied over time? From a dogmatic approach to law, the methodology of qualitative approach was used, based on documentary analysis of doctrine and jurisprudence. It was concluded that a jurisprudential change is legitimate yes and only yes when it meets the burden of transparency and the burden of argumentation. In addition, although unification judgments are a necessary mechanism to guarantee the right to equality and legal certainty, they also require the modulation of their effects over time, moving from retroactive to prospective application, based on a rights-based approach.

Keywords: Jurisprudential changes; unification judgments; Council of State; Constitutional Court; retroactivity: retrospectivity; prospectivity.

\section{Introducción}

En el ejercicio del derecho pretoriano de los jueces (López Medina, 2018) hay un abanico de decisiones que deben ser tomadas por la judicatura. Según Wróblewski (1985) son cinco los tipos de decisiones: Cuatro respecto de la disposición normativa (Sobre validez, interpretación, subsunción, y consecuencias) y una con relación a los hechos (decisión sobre pruebas). Primero, la decisión sobre validez implica que la norma a aplicar guarde armonía formal y sustancial con el ordenamiento jurídico. Segundo, la decisión interpretativa se da respecto del significado de la norma a aplicar en el caso concreto. Tercero, la decisión de subsunción determina si los hechos probados encajan en los supuestos fácticos consagrados por la norma a aplicar. Cuarto, la decisión sobre consecuencias gira en torno a la aplicación de los efectos dispuestos por la norma. Quinto, la decisión sobre pruebas tiene lugar con relación a la acreditación de los hechos que son los supuestos fácticos de la norma a aplicar.

En la medida en que los operadores jurídicos deben tomar distintas decisiones de las que habla Wróblewski (1985), es entendible que en ocasiones ante un mismo caso lleguen a conclusiones diferentes. Entre otras razones porque la práctica del derecho consiste en dar buenas razones para persuadir al interlocutor. Algo propio del pensamiento cetético, y no del dogmático, cuya pretensión es demostrar (Theodor Viehweg, 2007, citado por Gaviria Díaz, 2018¹).

Constantemente la judicatura debe tomar las decisiones enunciadas por Wróblewski (1985) y Gaviria Díaz (2018). La distinción entre el pensamiento dogmático (deductivo, axiomático) y el cetético (aporético) permite entender que en el derecho no existen verdades reveladas. Sólo hay posturas que pueden ser más o menos razonables dependiendo de los argumentos planteados. Por tanto, surgen fuertes debates al interior de las salas de decisión de tribunales y cortes. Los desacuerdos dan origen a las aclaraciones y salvamentos de voto² (Bravo Restrepo, 2000). Tales mecanismos reflejan el disenso de la posición mino-

1 “[...] ¿Qué es cetético, por oposición a dogmático? En el pensamiento dogmático, deductivo, axiomático, las cosas tiene lugar de esta manera: yo me ubico dentro de un sistema y dentro ese sistema todos los problemas que se plantean tienen solución, una solución ya dada y a mí me toca entonces extraer la solución; muy parecido a lo que decían los exégetas. En el pensamiento cetético o aporético ¿qué es lo que prevalece? Todo lo contrario. A mí se propone un problema y lo que yo voy a hacer es buscar el sistema que dé una solución más adecuada al problema que tengo; más adecuada de acuerdo con los valores políticos que informan mi conducta, de acuerdo con la visión que yo tengo del mundo" (pág. 74).

2 “Fíjense una vez más lo que rescato: de una parte, el elemento político; la sentencia no es únicamente un acto jurídico sino un acto político; dentro de ese esquema abierto de interpretación podemos encontrar varias sentencias; podría haber sido otra la decisión. ¿Por qué? Por distintas maneras de sentir de vivir la ética, la política, el valor de la libertad, etc. Algunos más bien aseguran el valor del orden, la prevalencia del interés general sobre el particular, aunque desde luego yo no acepto ese argumento; de todas maneras podemos concluir eso, no podemos tener la pretensión de que la sentencia que se dictó es innegable y que es la única posible. No. Es una de las tantas sentencias posibles. Y ¿qué tenemos que hacer? Tanto nosotros, los magistrados al dictar la sentencia, como los otros, dar argumentos que persuaden a la gente de que ese punto de vista es compatible con el ordenamiento jurídico; y no solo de que es compatible con nuestra 
Los cambios jurisprudenciales evidencian la diversidad de criterios y soluciones frente a un mismo hecho y problema jurídico ${ }^{3}$ (Cuesta Simanca, 2012) (Cuesta Davu, 2016) (Quinche, 2020). Asunto que es propio del ordenamiento jurídico colombiano que propende a la veleidad jurisprudencial, entendida como los casos donde la jurisprudencia ha sido oscilante y vacilante, tanto por razones legítimas como ilegítimas (Ospina Garzón, 2014).

El otro asunto controversial es, ¿Cómo se aplica en el tiempo el cambio jurisprudencial de las sentencias de unificación de la Corte Constitucional y el Consejo de Estado? Lo cierto es que en Colombia aún no se ha definido con claridad un criterio temporal al respecto (Ospina, 20144) (Serrato, 2019) (Ricardo Ezqueda, 2018).

El objetivo general de este escrito es analizar la modulación de los efectos en el tiempo de los cambios jurisprudenciales de las sentencias de unificación del Consejo de Estado y la Corte Constitucional de Colombia. Para ello, primero se hace una descripción de la ubicación del precedente judicial dentro del sistema de fuentes del ordenamiento jurídico colombiano en el siglo XXI. Luego, se presenta un marco general sobre las sentencias de unificación del Consejo de Estado y la Corte Constitucional. Por último, se identifican las distintas formas de aplicación en el tiempo de los cambios jurisprudenciales de estas dos altas cortes. Desde un enfoque dogmático del derecho, se empleó la metodología de enfoque cualitativo, a partir de análisis documental de la doctrina y jurisprudencia.

\section{La ubicación del precedente judicial dentro del sistema de fuentes del ordena- miento jurídico colombiano en el siglo XXI}

Hay pluralidad de categorías relacionadas con el derecho judicial. El sentido de cada una de estas depende de la jurisdicción desde donde se ubique el intérprete. A pesar de que la Corte Constitucional, el Consejo de Estado y la Corte Suprema de Justicia usen frecuentemente categorías como jurisprudencia, doctrina constitucional, doctrina probable, doctrina legal probable, doctrina legal, precedente judicial, sentencias, sentencias de unificación, subreglas, ratio decidendi, precedente administrativo, providencias judiciales, sentencias de altas cortes, entre otras., el sentido de cada una de ellas depende del del ámbito jurisdiccional (Quinche, 20205). Entre otras razones por la estructura constitucional de cada una de estas tres altas cortes.

Constitución, sino de que es un punto de vista plausible, que es bueno que se haya dictado ese fallo.

Los magistrados que salvaron el voto ¿qué hacen? Argumentaron en el sentido contrario para lograr que otro fallo también hubiera sido posible y que hubiera sido mejor, hubiera producido mejores resultados. ¿Qué se está haciendo? No se está demostrando, se está tratando de persuadir, se está haciendo más retórica que lógica..." (Gaviria Díaz, 2018, pág. 74-75).

3 “Toda sentencia está constituida por dos elementos: un elemento jurídico-cognosctivo: yo primero conozco el acto a partir del cual voy a crear; y segundo, un elemento político que significa un elemento decisorio; que el juez tiene capacidad decisoria; y cuando tengo capacidad decisoria es porque tengo capacidad de optar A, B, C y elijo una; y cuando elijo estoy realizando un acto típicamente político, un acto de decisión, al cual incorporo, desde luego, mi cosmovisión, la manera como veo el mundo, los valores éticos que informan mi conducta, a los cuales yo adhiero, los valores políticos que mueven mi conducta, etc. Eso hace parte constitutiva y no es un elemento espurio, sino un elemento legítimo del derecho.

Cuando se dice, por ejemplo, que un fallo tiene un contenido político, ordinariamente se hace dándole a ella un tono peyorativo, despectivo, de censura, cuando en realidad tiene necesariamente un elemento político, un contenido político que es ese: el juez tiene capacidad de optar. ¿Por qué el juez A y el juez B fallan de manera diferente? Porque, siendo reductibles las dos sentencias a una norma jurídica, los jueces tienen una cosmovisión distinta, un concepto distinto de la justicia, de la moral y todo eso es legítimo dentro del derecho. No hay que asombrarse, no hay que escandalizarse de que las cosas sean de ese modo". (Gaviria Díaz, 2018, pág. 69-70).

4 “Sin embargo, los cambios constantes de jurisprudencia, así sean expresos y motivados, crean inseguridad jurídica, de manera particular cuando son retroactivamente aplicados a hipótesis consolidadas cuando la posición jurisprudencial era diferente. Frente a esta situación, aunque la jurisprudencia comienza ya a estar consciente del problema, nada se prevé legalmente para evitar la retroactividad de los cambios de jurisprudencia: de posición o de parecer" (Ospina, 2014, pág. 22).

5 "Lo que se entienda por "precedente", "jurisprudencia" o "línea jurisprudencial" se ha vuelto problemático, en el sentido que cada una de las corporaciones viene dando significado y matizando cada una de las expresiones, conjuntándola con otras variables". (Quinche, 2020, pág. 134). 
Se debe partir desde la categoría más amplia, y luego descender a aquella más concreta. La categoría macro es la de providencias judiciales, la cual incluye autos y sentencias, que son los tipos de decisiones que toman todos los jueces de la República de Colombia, sin distinción de su rango jerárquico, especialidad, ubicación, composición, etc. En el universo de las providencias judiciales es menester diferenciar entre el precedente judicial y la jurisprudencia (Deik, 20186). El precedente judicial puede ser entendido como "la decisión anterior de una autoridad que fija posición interpretativa en relación con ciertas circunstancias fácticas y jurídicas, para ser aplicadas en el futuro, esto es, como antecedente vinculante generador de regla, principio o concepto aplicable a casos sustancialmente similares" (Santofimio Gamboa, 2010, pág. 10). Esta definición coincide con la sentencia T- 292 de 2006:

de allí que se pueda definir el precedente aplicable, como aquella sentencia anterior y pertinente cuya ratio conduce a una regla - prohibición, orden o autorización- determinante para resolver el caso, dados unos hechos y un problema jurídico, o una cuestión de constitucionalidad específica, semejantes.

Por lo general el precedente judicial hace alusión a un caso del pasado ya decidido por la autoridad jurisdiccional, el cual es similar a los hechos del caso presente que requiere solución. En cambio, la jurisprudencia corresponde al universo de decisiones emitidas por las altas cortes (Taruffo, 20077). De manera que el precedente judicial es la especie, y la jurisprudencia es el género.

Sin embargo, no toda la sentencia precedente tiene fuerza vinculante. Sólo su ratio decidendi, también conocida razón de la decisión del caso analizado o subregla ${ }^{8}$. Al respecto, Uprimny et al. (2006, pág. XIX) afirman que:

El concepto de "sub-regla" tiene un origen curioso en el constitucionalismo colombiano.

Al parecer, esa expresión no es usada en otros países, o lo es de manera tangencial. En cambio, en Colombia es utilizada masivamente en las discusiones constitucionales, en algunos artículos académicos y en ciertas jurisprudencias, como si fuera un concepto común y aceptado en la teoría constitucional. Pero no es así. Además, no es claro ni el origen ni la paternidad conceptual de esta noción. Sin embargo, a pesar de eso, es una categoría útil porque en el fondo corresponde a la noción de norma adscrita de Alexy, y es vecina a la idea de ratio decidendi en los sistemas del Common Law. Entendemos

6 "Los términos "jurisprudencia" y "precedente" son distintos, en cuanto el primero tiene naturaleza persuasiva y argumentativa, mientras que el segundo tiene carácter normativo y obligatorio. No se utiliza aquí, entonces, el concepto de precedente en sentido amplio que expone Iturralde -el que incluye tanto los obligatorios como los persuasivos-. Tampoco la concepción de Henao, quien asimila los conceptos de jurisprudencia y precedente, sin ahondar en la obligatoriedad de las decisiones judiciales para los casos futuros ni en el deber de justificación que debe satisfacer el juez del futuro que pretenda separarse del caso anterior". (Deik, 2018, pág. 141).

7 “Antes que nada, existe una distinción de carácter, por así decirlo, cuantitativo. Cuando se habla del precedente se hace generalmente referencia a una decisión relativa a un caso particular, mientras que cuando se habla de la jurisprudencia se hace, generalmente, referencia a una pluralidad, a menudo bastante amplia, de decisiones relativas a varios y diversos casos concretos. La diferencia no es solo de tipo semántico. El hecho es que en los sistemas que tradicional y típicamente se fundamentan en el precedente, generalmente la decisión que se asume como precedente es una sola; mas aún, pocas decisiones sucesivas son citadas para sostener el precedente. De este modo, es fácil identificar cual decisión verdaderamente "hace precedente". En cambio, en sistemas como el italiano, en los que se alude a la jurisprudencia, se hace referencia generalmente a muchas decisiones.

De otra parte, como sucede a menudo, la cantidad condiciona la calidad, lo que lleva al punto de establecer una diferencia cualitativa entre precedente y jurisprudencia. El precedente provee una regla - susceptible de ser universalizada, como ya se ha dicho- que puede ser aplicada como criterio de decisión en el caso sucesivo, en función de la identidad o, como sucede regularmente, de la analogía entre los hechos del primer caso y los hechos del segundo caso. Naturalmente la analogía entre los dos casos es afirmada o excluida por el juez del caso sucesivo según retenga prevalentes los elementos de identidad o los elementos de diferencia entre los hechos de los dos casos. Es por lo tanto el juez del caso sucesivo el que establece si existe o no existe el precedente, y entonces, por así decirlo, "crea" el precedente. Aparte de este perfil -sobre el cual regresaré en seguida- permanece claro que la estructura fundamental del razonamiento que llega a aplicar el precedente al caso sucesivo se funda en el análisis de los hechos. Si este análisis justifica la aplicación en el segundo caso de la ratio decidendi aplicada en el primero, el precedente es eficaz y puede determinar la decisión del segundo caso. Se observa que cuando se verifican estas condiciones, un solo precedente es suficiente para fundar la decisión del caso sucesivo". (Taruffo, 2007, pág. 87, 88).

8 "Son formulaciones que permiten aplicar el derecho abstracto a un caso concreto a través de reglas jurídicas prescriptivas, generales y abstractas. Por ejemplo, cuando un juez concede la tutela de un pensionado de la tercera edad y ordena el pago inmediato de las mesadas, el juez está aplicando una subregla, ya que está tomando el texto constitucional, que es muy general, y aplicándolo a una situación concreta" (Olano, 2004, pág. 596). 
entonces en esta investigación por "sub-regla" a la regla jurisprudencialmente construida por los jueces para solucionar casos concretos, y que puede ser considerada una norma adscrita. Por ello es una "sub-regla", porque es una formulación normativa jurisprudencial que indica las condiciones de aplicación de las reglas y principios constitucionales.

En Colombia el reconocimiento de la fuerza vinculante del precedente no fue un asunto pacífico. Debido al peso de la tradición de la familia del Civil Law se requirió más de 100 años para llegar a la cultura del precedente judicial vinculante de hoy; tal como lo ilustra López Medina (20099). De manera que en el siglo XXI el sistema de fuentes involucra rasgos del Common Law y del derecho continental europeo (Uprimny et al, 2006), entre otras razones, gracias a la labor hermenéutica de la Corte Constitucional.

A partir de la sentencia C-836 de 2001 el sistema de precedente judicial tuvo una profunda transformación "en tanto traduce el precedente judicial en nuestro sistema de fuentes de derecho, sin restringirlo ya a la jurisprudencia de la Corte Constitucional" (Contreras Calderón, 2011). Adicionalmente, en la sentencia C-539 de 2011 se hizo extensible el deber de acatamiento de las autoridades administrativas del precedente judicial

En síntesis, en virtud de la mutación constitucional de los artículos 230 (sistema de fuentes en el ordenamiento jurídico colombiano), y 13 (derecho a la igualdad) de la Constitución Política de 1991, los jueces deben dar aplicación uniforme a casos semejantes decididos en precedentes verticales y horizontales ${ }^{10}$ (Linares, 2017). En el primero el juez debe ser coherente con las decisiones que venía tomando respecto de determinado asunto fáctico y jurídico. En el segundo, en principio, el juez debe seguir la línea jurisprudencial decantada por sus superiores funcionales (altas cortes ${ }^{11}$ ).

Según Quinche (2020), Colombia ha implementado un sistema relativo de precedentes judiciales, tanto verticales como horizontales, considerándolos con fuerza vinculante para todos los jueces de la República. Esto no afecta el ejercicio del principio de autonomía e independencia de los jueces, quienes pueden apartarse de las líneas jurisprudenciales trazadas previamente siempre y cuando esgriman justificaciones suficientes y adecuadas. Pero ¿Cómo apartarse válidamente del precedente judicial obligatorio ? $^{12}$ (Whittaker, 2008)

9 “(...) En Colombia este concepto de precedente judicial ha tenido una constante evolución. Se inicia "adoptando la doctrina legal española en 1887 para terminar, en 1896, inclinándose por un "sistema libre" de influencia francesa. Este sistema libre domina con claridad todo el siglo XX y constituye una de las características centrales de la cultura jurídica colombiana. El sistema libre de jurisprudencia es reforzado por el texto tradicionalista del artículo 230 de la constitución de 1991 y luego confirmado por dos sentencias de constitucionalidad de la Corte: esta constelación de normas tiene suficiente fuerza para hacer prevalecer, hasta 1995, la tesis clásica sobre el valor auxiliar de la jurisprudencia. A esta visión se oponen, como ya se ha visto, el ejecutivo nacional, mediante su decreto reglamentario de los procedimientos ante la Corte (D.2067/91) y al menos un magistrado de la Corte (Ciro Angarita), que en sus sentencias de tutela despliega una cláusula decisional, donde pretende hacer obligatoria la ratio decidendi de sus fallos a casos futuros análogos por sus hechos o circunstancias. Esta línea de argumentación a favor del valor obligatorio del precedente de tutela es derrotada tempranamente mediante la declaratoria de inexequibilidad del artículo 23 del Decreto 2067 de 1991. Este estado de cosas continuara hasta 1995., cuando comienza la reacción por parte de algunos de los magistrados (Gaviria y Cifuentes, principalmente). Con ellos se inicia una reconstrucción de la obligatoriedad de la jurisprudencia a través de la utilización del concepto de "doctrina constitucional" y del principio de igualdad (Art 13 C.P). Esta línea argumentativa termina triunfando al interior de la Corte, que finamente anuncia de manera unánime una doctrina del valor del precedente (Sent. C-037/96)". (pág. 160).

10 “Existe en el país, una sólida línea jurisprudencial en la que se ha venido reconociendo que el precedente es vinculante para las autoridades judiciales, por lo que, siguiendo la doctrina, podría afirmarse que sobre el artículo 230 Superior ha ocurrido un desplazamiento del sistema de fuentes, definido como una mutación constitucional, pues a pesar de que su texto se mantiene intacto, su sentido y alcance dista de ser el que su literalidad señala. En efecto, la Corte Constitucional señalando que el "imperio de la ley" al que hace referencia el artículo 230 ha de entenderse de manera amplia y ha proferido una serie de fallos que han incorporado la teoría del precedente, dándole especial preponderancia dentro del sistema de fuentes del derecho" (Linares, 2017, pág. 8).

$11 \mathrm{Si} \mathrm{bien} \mathrm{las} \mathrm{tres} \mathrm{son} \mathrm{órganos} \mathrm{de} \mathrm{cierre} \mathrm{en} \mathrm{sus} \mathrm{respectivas} \mathrm{jurisdicciones,} \mathrm{la} \mathrm{Corte} \mathrm{Constitucional} \mathrm{y} \mathrm{la} \mathrm{Corte} \mathrm{Suprema}$ de Justicia si fungen como genuinos tribunales de unificación de jurisprudencia. La primera en ejercicio del control de constitucionalidad abstracto (sentencias tipo C) y concreto (sentencias tipo T y SU) (Barrero, 2018). La segunda con sentencias que resuelven los recursos extraordinarios de casación en materia civil-familia, laboral, y penal. Sin embargo, el Consejo de Estado conserva un rol mixto al ser tanto juez de unificación como juez de instancia (Ospina, 2014). 
Mediante dos posibilidades: 1) Con la distinción de la ratio decidendi, entendida como la regla o principio normativo abstracto que sustentó la decisión del caso (Uprimny et al, 2006). El juez actual interpreta de forma distinta la subregla del caso anterior. De manera que el juez posterior define la subregla del juez precedente. 2) Con la distinción de los hechos del caso por resolver. Cuando para el juzgador los hechos del caso actual difieren a los hechos del caso anterior.

Así es claro que en la actualidad el precedente judicial cuenta con una importante posición dentro del sistema de fuentes del ordenamiento jurídico colombiano, en tanto trasciende del criterio auxiliar inicialmente planteado en la disposición gramatical del artículo 230 superior constitucional, para convertirse en una genuina fuente principal a tenor de lo planteado en los artículos 10 (deber de aplicación uniforme de las normas y la jurisprudencia), 102 (procedimiento administrativo de extensión de jurisprudencia), 269 (mecanismo judicial de extensión de jurisprudencia del Consejo de Estado) y 270 (sentencias de unificación jurisprudencial) de la Ley 1437 de 2011, y 7 de la Ley 1564 de $2012^{13}$ (declarado exequible en la sentencia C-621 de 2015).

\section{Marco general sobre las sentencias de unificación jurisprudencial del Consejo de Estado}

El precedente horizontal exige que los jueces resuelvan uniformemente casos con el mismo criterio aplicado a litigios resueltos por ellos en el pasado. Por su parte, y debido a la estructura del poder judicial colombiano, en el precedente vertical existe el deber de aplicar las reglas definidas por los jueces superiores al decisor en casos semejantes al que está en cierne. De manera que en la jurisdicción ordinaria (civil, laboral, penal, familia) los jueces municipales deben acatar lo resuelto por jueces de circuito. Los jueces de circuito deben acatar lo resuelto por los tribunales superiores de distrito judicial. Y los tribunales superiores de distrito judicial deben acatar lo resuelto por la Corte Suprema de Justicia en sus tres salas de decisión. Y la Corte Suprema de Justicia debe obedecer lo resuelto por la Corte Constitucional. Es decir, en la jurisdicción ordinaria hay por lo menos cuatro niveles distintos de precedentes judiciales verticales.

El asunto es un poco distinto en la jurisdicción de lo contencioso administrativo, donde el precedente judicial vertical opera sólo en tres niveles: Primero, de los jueces administrativos hacia los tribunales administrativos. Segundo, de los tribunales administrativos hacia

12 "Esto significa, primero, que los hechos de un caso componen algo que excede con mucho un simple contexto: ellos juegan una función decisiva al determinar la fuerza futura del proceso. Así, la fuerza obligatoria del precedente reconoce la particularidad inherente de todo desarrollo jurídico efectuado en el curso del litigio, en el cual los jueces tienen en mente las circunstancias y, puede decirse, el resultado deseado del pleito de que conocen. ¿Quién, sin embargo, determina la ratio de un caso? En ciertas ocasiones uno o más jueces en la misma causa tratarán de aclarar lo que consideran como las proposiciones jurídicas críticas para su resolución, quizá incluso explicando la extensión de estas y comentando explícitamente su relación con el Derecho en general. No obstante, en definitiva corresponde a los jueces que conocen de procesos posteriores fallar basándose en las rationes decidendi de sentencias anteriores, identificando una o más proposiciones de Derecho que fueron necesarias para su decisión de los hechos según estos fueron establecidos por el tribunal anterior. En efecto, sobre todo cuando un tribunal posterior es de inferior jerarquía que el que resolvió el caso precedente, aquel debe determinar las proposiciones que configuraron su ratio para así seguirla. Como un corolario, existen dos maneras en que un tribunal posterior puede evitar la aparente aplicabilidad de una proposición jurídica tal como fue enunciada en un pleito anterior. Puede sostener que la proposición jurídica contenida en el caso precedente, que parece corresponder a los hechos de que conoce, no formó parte de la ratio del fallo anterior y, por tanto, no obliga; o puede declarar que la proposición jurídica en el caso precedente en realidad integró la ratio de la sentencia anterior, pero que los hechos del caso actual son distinguibles de los hechos del caso anterior, esto es, distintos en una forma jurídicamente relevante. En consecuencia, las proposiciones jurídicas contenidas en las sentencias inglesas se supeditan a los hechos en un doble sentido: su fuerza vinculante depende de su relación con los hechos del fallo en el cual ellos fueron declarados y de su relación con los hechos del juicio en que posteriormente se alega su aplicación. Dado que en último término son únicamente los tribunales posteriores quienes identifican las proposiciones jurídicas que aprueban este doble examen, puede notarse que la fuerza obligatoria de los precedentes es un tanto frágil como también contingente". (Whittaker, 2008) (Énfasis propio).

13 “ARTíCULO 7o. LEGALIDAD. Los jueces, en sus providencias, están sometidos al imperio de la ley. Deberán tener en cuenta, además, la equidad, la costumbre, la jurisprudencia y la doctrina.

Cuando el juez se aparte de la doctrina probable, estará obligado a exponer clara y razonadamente los fundamentos jurídicos que justifican su decisión. De la misma manera procederá cuando cambie de criterio en relación con sus decisiones en casos análogos".

El proceso deberá adelantarse en la forma establecida en la ley. 
En la jurisdicción constitucional también existen dos niveles de precedente judicial vertical. De los jueces de tutela de primera instancia con relación a los jueces de tutela de segunda instancia. Y de los jueces de segunda instancia respecto a las decisiones de revisión eventual proferidas por la Corte Constitucional.

Al interior de las tres jurisdicciones señaladas (ordinaria, de lo contencioso administrativo, y constitucional) también aplica el precedente judicial horizontal en sus diferentes salas de decisión, así como sus salas plenas.

Ahora, en particular es necesario dimensionar la composición del Consejo de Estado para entender qué tipos de providencias judiciales son emitidas en salas de decisión, y cuáles en sala plena, y el origen estructural de las discrepancias interpretativas, y el remedio de las sentencias de unificación. El Consejo de Estado es la corporación judicial con mayor número de magistrados (31), organizados en cinco salas: Sala plena (31 magistrados), sala de lo contencioso administrativo ${ }^{14}$ ( 27 magistrados), sala de consulta y servicio civil (4 magistrados), sala de gobierno (8 magistrados, "conformada por el Presidente y el Vicepresidente del Consejo de Estado y por los Presidentes de la Sala de Consulta y Servicio Civil y de las secciones de la Sala de lo Contencioso Administrativo", art. 107, Ley 1437 de 2011), y salas especiales de decisión (4 magistrados).

En el Consejo de Estado pueden existir tantos criterios jurisprudenciales como magistrados lo integran. En medio de tal diversidad de posturas surge la necesidad de las sentencias de unificación jurisprudencial. Sin embargo, esta figura no es totalmente nueva en el CPACA. Tiene sus orígenes en el precedente judicial de descongestión del artículo $114^{15}$ de la Ley 1395 de 2010 (López Medina, 2017).

La reformada Ley 1437 de $2011^{16}$ define las sentencias de unificación jurisprudencial a partir de dos criterios, uno sustancial y otro procesal. De acuerdo con el criterio sustancial tienen esta calidad aquellas providencias dictadas por importancia jurídica, transcendencia económica o social, o "por necesidad de unificar o sentar jurisprudencia precisar su alcance o resolver las divergencias en su interpretación y aplicación". En cambio, según el criterio procesal son sentencias de unificación las que resuelven los recursos extraordinarios, y mecanismos eventuales de revisión en acciones populares y de grupo.

Estas reglas de la Ley 1437 de 2011 muestran que hubo una reconfiguración en las fuentes del derecho administrativo (García López E., 2011), (Serna Mesa, 2010), (Quinche, 2020), gracias a la positivización de los precedentes judiciales (artículos 10, 102, 269 y 270 de la Ley 1437 de 2011; y 7 de la Ley 1564 de 2012), pasando de ser una fuente auxiliar

14 A su vez la sala de lo contencioso administrativo está dividida en cinco (5) secciones: La sección primera conformada por 4 magistrados. La sección segunda conformada por 6 , y dos subsecciones de tres magistrados cada una. La sección tercera por 9 magistrados, y tres subsecciones de tres magistrados cada una. La sección cuarta por 4 magistradas. Y la sección quinta por 4 magistrados (art. 110, Ley 1437 de 2011). Debido a esta estructura interna del Consejo de Estado existen por lo menos autos y sentencias de las subsecciones, secciones, y de la sala plena de lo contencioso administrativo. Dentro de cada una de ellas pueden surgir las sentencias de unificación jurisprudencial de que trata el artículo 270 del CPACA.

15 "Las entidades públicas de cualquier orden, encargadas de reconocer y pagar pensiones de jubilación, prestaciones sociales y salariales de sus trabajadores o afiliados, o comprometidas en daños causados con armas de fuego, vehículos oficiales, daños a reclusos, conscriptos, o en conflictos tributarios o aduaneros, para la solución de peticiones o expedición de actos administrativos, tendrán en cuenta los precedentes jurisprudenciales que en materia ordinaria o contenciosa administrativa, por los mismos hechos y pretensiones, se hubieren proferido en cinco o más casos análogos".

16 "ARTÍCULO 270. SENTENCIAS DE UNIFICACIÓN JURISPRUDENCIAL. <Artículo modificado por el artículo 78 de la Ley 2080 de 2021. El nuevo texto es el siguiente:> Para los efectos de este Código se tendrán como sentencias de unificación jurisprudencial las que profiera o haya proferido el Consejo de Estado por importancia jurídica o trascendencia económica o social o por necesidad de unificar o sentar jurisprudencia precisar su alcance o resolver las divergencias en su interpretación y aplicación; las proferidas al decidir los recursos extraordinarios y las relativas mecanismo eventual de revisión previsto en el artículo 36A de la Ley 270 de 1996, adicionado por el artículo 11 de la Ley 1285 de 2009". 
para convertirse en fuente principal vinculante. Tanto así que las sentencias de unificación del Consejo de Estado (que reconocen un derecho subjetivo) permiten acudir en sede administrativa al mecanismo de extensión de la jurisprudencia a terceros (artículo 102, Ley 1437). Si la entidad pública niega la extensión de los efectos de la sentencia de unificación, entonces procede el mecanismo judicial ante el Consejo de Estado (artículo 269, Ley 1437 de 2011). Por estas razones Tamayo (2011, pág. 1799) afirmó que “Es la Ley 1437 de 2011, la que se despacha a favor del precedente obligatorio, hasta el punto de que en algunas de sus disposiciones la Ley pareciera carecer de sentido".

Entre los años 1998 y 2021 el Consejo de Estado ha proferido 121 sentencias de unificación jurisprudencial en asuntos laborales, de responsabilidad extracontractual del Estado, tributarios, contractuales, de protección de derechos colectivos, disciplinarios, entre otros $^{17}$.

\section{Marco general sobre las sentencias de unificación de la Corte Constitucional}

En Colombia a partir de la Constitución de 1991 se creó la Corte Constitucional, y con ella un nuevo sistema de control de constitucionalidad abstracto y concreto (Benavidez, 2020).

A través del control abstracto el tribunal constitucional se encargaría de decidir las demandas públicas de inconstitucionalidad, presentadas por ciudadanos en contra de leyes (artículo 241-4 C.P.), decretos con fuerza de ley dictados por el Gobierno (artículo 241-5 C.P.), actos legislativos de reforma constitucional (artículo 241-1 C.P.), etc. Mientras que con el control concreto la Corte Constitucional realizaría la función de revisar, previa selección eventual, decisiones judiciales relacionadas con acciones de tutela presentadas en todos los despachos judiciales del país (artículo 241-9 C.P.). (Benavidez, 2020, pág. 5).

La Corte Constitucional está integrada por una sala plena de 9 magistrados (art. 239 superior, art. 44 Ley 270 de 1996), y 9 salas de decisión de tres magistrados cada una. En el control de constitucionalidad abstracto emite sentencias tipo C, cuando examina la conformidad o no de una norma jurídica con la Constitución Política. Mientras que en el control concreto hace una revisión eventual de los fallos de tutela de instancia, mediante sentencias tipo T y SU. La primera es emitida por una de las salas de decisión, mientras que las segundas por la sala plena de la corporación en el ejercicio de su labor interpretativa de los derechos fundamentales (Benavidez, 2020). Al respecto, el Decreto Ley 2591 de 1991 (artículo 34) y el Acuerdo 02 de 2015 (artículo 61) establen que los cambios jurisprudenciales en sede de tutela sólo pueden ser realizados por la sala plena de la corporación.

ARTICULO 34. DECISION EN SALA. La Corte Constitucional designará los tres Magistrados de su seno que conformarán la Sala que habrá de revisar los fallos de tutela de conformidad con el procedimiento vigente para los Tribunales del Distrito Judicial. Los cambios de jurisprudencia deberán ser decididos por la Sala Plena de la Corte, previo registro del proyecto de fallo correspondiente.

Artículo 61. Revisión por la Sala Plena. Cuando a juicio de la Sala Plena, por solicitud de cualquier magistrado, un proceso de tutela dé lugar a un fallo de unificación de jurisprudencia o la transcendencia del tema amerite su estudio por todos los magistrados, se dispondrá que la sentencia correspondiente sea proferida por la Sala Plena. Adicionalmente, para los fines establecidos en las normas vigentes, después de haber sido escogidos autónomamente por la Sala de Selección competente, los fallos sobre acciones de tutela instauradas contra providencias de la Corte Suprema de Justicia y del Consejo de Estado deberán ser llevados por el magistrado a quien le corresponda en reparto a la Sala Plena, la cual determinará si asume su conocimiento con base en el informe mensual que le sea presentado a partir de la Sala de Selección de marzo de 2009. En tal evento, el magistrado ponente registrará en la Secretaría el proyecto de fallo respectivo y se procederá a cumplir el mismo trámite previsto por el artículo

17 Recuperado de http://servicios.consejodeestado.gov.co/testmaster/nue_unifi.asp 
53 del Reglamento de la Corporación para el cambio de jurisprudencia, en materia de sentencias de revisión de tutela.

En el año 2019 la Corte Constitucional publicó un compendio de todas sus sentencias de unificación de tutela entre los años 1993 y $2019^{18}$.

Hasta aquí se han abordado algunos tópicos de las sentencias de unificación del Consejo de Estado y la Corte. El siguiente acápite alude a los cambios jurisprudenciales de este tipo de provincias, y la aplicación de sus efectos en el tiempo.

\section{La aplicación en el tiempo de los cambios jurisprudenciales}

Para entender a cabalidad las sentencias de unificación del Consejo de Estado y la Corte Constitucional se debe tener en cuenta su estructura, integrada por los hechos del caso, el problema jurídico a resolver, y su parte resolutiva (López Medina, 2017), (Uprimny et al, $2006^{19}$ ). La parte motiva está conformada mayormente por dichos de paso (obiter dicta), y unas cuantas líneas de la razón de la decisión (ratio decidendi). En cambio, la parte resolutiva corresponde a la solución del caso (decisum).

La parte motiva de la decisión judicial contiene la relación de los hechos, de las pruebas, y las razones que sustentan la solución del caso, contenida en la parte resolutiva (Dueñas, 2015, pág. 176). Mientras que la parte resolutiva decide la controversia planteada en el problema jurídico, declarando la prosperidad de las pretensiones del demandante, o de las excepciones del demandado. En el primer evento, dictando ordenes consecuenciales, a solicitud de parte, o bien sea concediendo más allá de lo pedido (ultra petita), o por fuera de lo pedido (extra petita) (Dueñas, 2015).

El uso del precedente judicial puede ser diverso, con el fin de reiterar, ampliar, restringir, distinguir, o apartarse de las subreglas definidas en casos pasados que ya han sido resueltos (López Medina, 2018). Este apartamiento origina los cambios jurisprudenciales, que pueden obedecer a argumentos legítimos o no. Ospina (2014) afirma que las razones legítimas son dos: i) Defectos de la norma escrita. ii) autonomía e independencia del juez. En cambio, entre las razones ilegítimas se encuentra un sistema jurídico que facilita la veleidad (Por personalización de la jurisprudencia, carencia de estudios jurisprudenciales dentro y fuera de la jurisdicción, y problemas de las decisiones precedentes); y la desviación de poder jurisdiccional (por actos de corrupción, o fines ajenos a la competencia jurisdiccional). Por tanto, los cambios jurisprudenciales exigen aclarar cuándo están legitimados o no (Ospina, 2014).

En cambio, para López Medina (2018) las justificaciones son suficientes y adecuadas cuando corresponden a interpretaciones legítimas de los precedentes judiciales, teniendo en cuenta los criterios de obediencia, distinción fáctica, distinción de la ratio decidendi, indeterminación de la jurisprudencia previa, y propiamente el cambio de jurisprudencia.

18 Recuperado de https://www.d1tribunaladministrativodelmagdalena.com/images/Sentencias\%20de\%20Unificacion/Constitucional/Sentencias_de_unificacion.pdf Para consultas las sentencias de unificación incluso hasta el 2021 ver https://www.corteconstitucional.gov.co/relatoria/SU.php

19 "Este tipo de seguimiento jurisprudencial es hoy insuficiente, pues, debido a la fuerza creciente del precedente, los hechos de los casos han adquirido una importancia cada vez mayor en la discusión de las sentencias, por lo que los "extractos" jurisprudenciales no pueden entenderse adecuadamente, sin tomar en consideración los hechos o pretensiones del caso, el problema abordado por la alta corte y el tipo de decisión tomada" (Uprimny et al, 2006, pág. XVIII). 
Tabla Nro. 1.

Tipos de argumentos respectos de la interpretación de los precedentes judiciales

\begin{tabular}{|l|l|}
\hline \multicolumn{1}{|c|}{ Argumentos ilegítimos } & \multicolumn{1}{c|}{ Argumentos legítimos } \\
\hline -Negación del valor general de la jurisprudencia & -Obediencia al precedente \\
-Ignorancia de la jurisprudencia vigente & -Distinción fáctica de hechos relevantes \\
-Desobediencia o renuencia frente a la jurispru- & -Distinción entre ratio decidendi y obiter dictum \\
dencia & -Indeterminación de la jurisprudencia previa \\
& -Cambio de jurisprudencia \\
\hline
\end{tabular}

Fuente: López Medina (2018, pág. 206)

De tal suerte que no todo cambio jurisprudencial, incluso de altas cortes, es legítimo. En sentido contrario, cuando se presentan cambios jurisprudenciales ilegítimos el ordenamiento jurídico colombiano consagra mecanismos de control (López Medina, 2017²0).

Desconocer el precedente judicial o cambiarlo injustificadamente constituye una causal especial de procedibilidad de la acción de tutela contra providencias judiciales, o causal de anulación de las sentencias de la Corte Constitucional, respectivamente, dependiendo sea el caso. Es lo primero si el cambio jurisprudencial es realizado por cualquier autoridad jurisdiccional (desde los jueces municipales hasta las altas cortes), excepto la Corte Constitucional, porque ella tiene su propio mecanismo control inter orgánico. Es lo segundo si el cambio ilegítimo proviene de la misma Corte.

Por tanto, las implicaciones de los cambios jurisprudenciales varían de acuerdo con la alta corte implicada. De manera que la Corte Constitucional tiene mayor ámbito de decisión para cambiar sus tesis jurisprudenciales, en comparación con los otros tribunales supremos. Esto debido al objeto de su interpretación: la Constitución Política. Situación que hace necesario analizar de forma diferenciada los cambios jurisprudenciales de la Corte Constitucional, el Consejo de Estado, la Corte Suprema de Justicia.

Pero ¿Qué son los cambios jurisprudenciales? De acuerdo con Cuesta Simanca (2012), estos aluden a

la modificación que de sus decisiones hacen las altas cortes en casos similares a los decididos con anterioridad por ellas mismas". Es decir, tomar en un caso una decisión distinta a la que se tomó en uno anterior pero similar, entendiendo por similar aquel caso con supuestos fácticos semejantes al anterior, originados en un mismo contexto social y jurídico. Es un cambio en la decisión, no en los hechos que originaron el conflicto, ni en las normas aplicables ni en el contexto en el que aquellos tuvieron lugar, ya que si alguno de los tres últimos cambia (hecho, norma o realidad social), se trataría de un caso distinto que difiere del anterior en alguna propiedad relevante (distinguish) y que, por tanto, merece una decisión diferente. No sería propiamente un cambio de jurisprudencia. (pág. 86-87)

Esta definición, enfatiza que únicamente hay cambio jurisprudencial cuando a pesar de que entre el caso anterior y el caso nuevo son similares los hechos, las normas aplicables y el contexto social, el operador jurídico cambia la decisión, o más propiamente la subregla²1.

20 Para López Medina (2017) los mecanismos de control a la incoherencia jurisprudencial son: 1) Revisión eventual de acciones de tutela, 2) Acción de tutela contra providencias judiciales, 3) Solicitudes de nulidad de sentencias de la Corte Constitucional, 4) Prevaricato por violación del precedente judicial.

21 la regla o principio que, más allá de las particularidades irrelevantes del caso, constituye la base directa de la decisión tomada en el caso concreto. Según la terminología acuñada en nuestra práctica jurídica nacional, la ratio decidendi serían las "sub-reglas" jurisprudenciales que se desprenden de las decisiones tomadas por la Corte. En cambio, aquellas consideraciones de la parte motiva que no determinaron la decisión previa son llamadas obiter dicta (dichos al pasar) (Uprimny et al, 2006, pág. XXIII). 
En similar sentido Cuesta Davu (2016) define los cambios jurisprudenciales como La modificación que de sus decisiones hacen tales cortes en casos similares a los decididos con anterioridad por ellas mismas. Es decir, tomar en un caso (caso 2 ) una decisión distinta a la de un asunto anterior (caso 1) pero similar, sin dejar de entender por similar la identidad de los supuestos fácticos que originaron el litigio, juzgados con las mismas normas jurídicas, en igual contexto histórico. Es un cambio en la decisión (un cambio de opinión) en un asunto que se resolvió de manera distinta a otro que guarda las similitudes señaladas. Si al comparar el caso 1 con el caso 2 se encuentra diferencia en alguno de los tres componentes descritos (hechos que generan la litis, normas aplicadas o escenario histórico), se lidiaría con conflictos distintos que, por lo tanto, merecen decisiones diferentes (distinguish anglosajón). No sería propiamente un cambio de jurisprudencia. (pág. 54)

Por su parte, Quinche (2020) sostiene que hay cambio de jurisprudencia cuando la Corte y los tribunales se apartan de sus propios precedentes horizontales y verticales.

Ospina (2014) indica que en sede de la jurisdicción de lo contencioso administrativo los cambios jurisprudenciales son manifestación de la veleidad del Consejo de Estado. Al punto de que el legislador consagró la exigencia de la transparencia y argumentación: "En virtud del principio de igualdad, todo cambio de la jurisprudencia sobre el alcance y contenido de la norma, debe ser expresa y suficientemente explicado y motivado en la providencia que lo contenga" (inciso tercero del artículo 103 de la Ley 1437 de 2011).

Así el cambio jurisprudencial esté suficientemente motivado y sea legítimo (López Medina, 2017), este crea inseguridad jurídica al ser aplicado de forma retroactiva a casos surgidos en vigencia de la subregla anterior ${ }^{22}$ (Ospina, 2014). Alvarado (2012, pág. 36) señala que "la cuestión principal y más problemática, por tanto, no es la de saber si el órgano emisor de la jurisprudencia puede o no cambiar la orientación. La cuestión crucial, es la de saber cómo y con qué efectos debe hacerlo".

La preocupación de Alvarado (2012) concierne a la aplicación en el tiempo de los cambios jurisprudenciales. Dicho en otras palabras, a la modulación de los efectos temporales de la variación de subreglas, así como lo ha hecho la Corte Constitucional en el control abstracto $^{23}$ (Armenta, 2014). Este asunto en ocasiones es omitido por los demás jueces. Y cuando no es así, se han aplicado tres efectos distintos (prospectivo, retrospectivo, y retroactivo). Este escrito plantea que en Colombia aún no se ha definido con claridad un criterio temporal con enfoque de derechos (Ospina, 2014; Serrato, 2019; Ricardo Ezqueda, 2018).

Hablar de los efectos de las sentencias en el tiempo implica valorar si estas tienen efectos ex nunc (prospectivo), ex tunc (retroactivo), o intermedio (retrospectivo). La aplicación ex nunc implica efectos desde ahora. La nueva decisión se aplicará a los casos de allí en adelante, tomando como punto de partida la fecha de esta o la de su publicación, notificación o comunicación. De manera que los litigios surgidos antes de tal fecha se regirán por la tesis jurisprudencial vigente al momento de acudir a la administración de justicia (presentación de la demanda). En cambio, en la aplicación con efectos ex tunc hay retroactividad (efectos desde entonces). Bajo esta perspectiva, la nueva subregla se aplica hacia atrás en el tiempo, abarcando aquellos casos que ya se habían sometido a consideración del aparato jurisdiccional. Es decir, los casos surgidos antes de esta fecha se regirán por la nueva subregla, y no por la anterior subregla vigente en ese momento.

22 "El verdadero problema consiste entonces en los casos en los que frente al mismo problema jurídico cambia frecuentemente de posición, ya que esto puede resultar en el mejor de los casos en un descuido o, en el peor, de un fenómeno de corrupción. Sea cual fuere la razón profunda de dichos cambios repentinos, hay que reconocer que dichos cambios de parecer -que no de jurisprudencia- son un ataque al principio de igualdad" (Ospina, 2014, pág. 39).

23 “Dicho de otro modo, la Corte como máximo juez constitucional ha previsto, hablando concretamente de los efectos en el tiempo de sus sentencias, otros distintos a la regla general de que son hacia futuro, pues en los casos en que esta lo determine, pueden ser retroactivos o de inconstitucionalidad diferida". (Armenta, 2014, pág. 60). 
Los cambios jurisprudenciales pueden aplicarse en el tiempo por lo menos bajo alguno de estos tres efectos: Efecto prospectivo, efecto retrospectivo, y efecto retroactivo (Serrato, 2019). Este último es el más problemático por la afectación de derechos fundamentales de los sujetos procesales involucrados, tales como la igualdad, la seguridad jurídica, la confianza legítima, y la buena fe (Ospina, 2014).

Con los ejemplos referidos se advierte que el Consejo de Estado cambia frecuentemente su jurisprudencia. Dichos cambios son aceptados por jueces y doctrinantes, quienes los tienen como ajustados al ordenamiento pues aseguran que con ellos se busca evitar la petrificación del orden legal y además, evitar que las equivocaciones del pasado sean las equivocaciones del presente y el futuro.No obstante, lo que pretende plantearse no hace hincapié en que la forma de pensar de quienes administran justicia cambie de rumbo frecuentemente, asunto que ciertamente forma parte de otro discurso. Lo que se resalta, es el efecto nocivo que trae consigo la aplicación retroactiva de dicho cambio y que es soslayado por aquellos, el cual consiste en que quienes siguen los lineamientos jurisprudenciales establecidos, adecuando sus actos procesales a ello, ven luego que su proceder es desconocido por quien lo prohijó, se les sorprende en el curso del litigio y se les ocasiona daños antijuridicos consistentes en la perdida de sus pretensiones, las cuales hubieran logrado si no se hubiese aplicado el nuevo criterio jurisprudencial. (Cuesta, 2012, pág. 113-114).

Efecto prospectivo: En el efecto prospectivo o de jurisprudencia anunciada, con este se apunta a que las decisiones deben tener efectos únicamente hacia el futuro, por lo tanto, no han de ablicarse al caso examinado, sino que solo para aquellos cuyos hechos ocurran de allí en adelante, o cuando menos, para aquellos casos cuya demanda sea presentada una vez ha entrado en vigor el nuevo precedente. (Serrato, 2019, pág. 13).

El Consejo de Estado ha aplicado el efecto prospectivo en algunos $\operatorname{casos}^{24}$, como ocurrió con la sentencia de unificación del 27 de junio de $2017^{25}$ (expediente 33.945), emitida por la Sala Plena de la Sección Tercera del Consejo de Estado, sobre la liquidación de perjuicios patrimoniales (lucro cesante) y por afectación a bienes convencional y constitucionalmente protegidos, causados por la muerte de personas dedicadas a la economía doméstica (Ri-

24 Para profundizar véase: Sección Primera, Subsección C, sentencia del 04 de febrero de 2021, 68001-23-33-0002020-00089-01(PI), C.P. Roberto Augusto Serrato Valdés. "117. Este criterio jurídico tendrá aplicación hacia el futuro y para los hechos acaecidos con posterioridad a esta providencia judicial y no para el caso concreto que en este proceso se juzga, en la medida en que deben respetarse los principios de seguridad jurídica y confianza legítima". Sección Tercera, Subsección C, sentencia del 14 de septiembre de 2018, expediente 53.392, C.P. Guillermo Sánchez Luque. "Aunque la variación de jurisprudencia por regla general tiene efectos sobre todos los casos a los que se aplica, no se puede desconocer que un nuevo criterio, aplicado a las demandas interpuestas con anterioridad, puede -como sucede en este caso- entrañar una afectación al derecho de acceso a la justicia, al imponer una carga desproporcionada al demandante, luego de muchos años de estar pendiente de una resolución de su controversia". Sección Tercera, Subsección C, sentencia del 25 de abril de 2018, expediente 58.890, C.P. Jaime Orlando Santofimio Gamboa. “5.5.- Entonces, la garantía de los derechos individuales en el marco de las actuaciones administrativas y jurisdiccionales lleva a afirmar por regla general que todo cambio de jurisprudencia que altera de manera sustantiva el contenido y alcance de las competencias estatales, de los derechos de las personas o los mecanismos de protección de los mismos, necesariamente debe ser adoptado e interpretado con efecto prospectivo o a futuro, esto es, que de manera ínsita se encuentra envuelto en él su radio de acción temporal o ratione temporis gobernando las situaciones problemáticas que se susciten a partir de la fecha posterior a su adopción, lo que excluye cualquier suerte de aplicación retroactiva del nuevo criterio jurisprudencial". Sección Tercera, Subsección B, sentencia del 25 de septiembre de 2017, expediente 50.892, C.P. Danilo Rojas Betancourth. Sección Tercera, Subsección C, sentencia del 04 de septiembre de 2017, expediente 57.279, C.P. Jaime Orlando Santofimio Gamboa. "Se apresta la Sala a pronunciarse sobre el valor del precedente judicial y la proscripción de aplicación retroactiva del mismo, habida consideración a que solo a esta altura del estado de cosas ha tomado conciencia suficiente, luego de diferentes pronunciamientos insulares sobre la materia, de advertir la necesidad de referirse de manera expresa a esta temática central para la labor adjudicativa y desentrañar la que considera es una regla general del oficio judicial: adjudicar los litigios conforme al derecho vigente; lo que resulta más que oportuno atendiendo las particularidades relevantes que plantea este contencioso, como se hace en los siguientes términos".

25 “Ahora bien, comoquiera que esta sentencia de unificación comporta una modificación jurisprudencial que tendría efectos en la tasación y liquidación de nuevos perjuicios frente a los cuales no operó el principio de contradicción, la Sala empleará la figura de la jurisprudencia anunciada y, por tal motivo, esta alteración del precedente solo será aplicable a los procesos que se inicien con posterioridad a esta providencia, en aras de garantizar los principios constitucionales al debido proceso y a la defensa de las entidades y sujetos demandados ante esta jurisdicción. Por tal motivo, la Sala no estudiará de fondo el reconocimiento de daños derivados a bienes convencional y constitucionalmente protegidos en el sub examine". 
cardo Ezqueda, 2018). Además, recientemente también aplicó la figura de la jurisprudencia anunciada, en la sentencia que decidió la demanda de nulidad electoral contra la elección de Francisco Roberto Barbosa Delgado como Fiscal General de la Nación para el periodo 2020-202426.

Efecto retrospectivo: Según Serrato (2019), el efecto retrospectivo implica un nivel intermedio entre la aplicación ex nunc y ex tunc, así:

que la nueva regla de precedente solo podrá afectar situaciones jurídicas que se encuentren en tránsito de ejecución, esto es, que se encuentren en curso o a la espera de un fallo judicial de modo tal que no se encuentren consolidadas. Así, los efectos retrospectivos implican por una parte, un efecto general inmediato y por otra, una aplicación retroactiva, pero limitada.

En este sentido, la sentencia de marzo de 2018 del Consejo de Estado antes citada explica que, de acuerdo con estos efectos, el nuevo precedente debe ser aplicado al caso que se está enjuiciando, y de allí en adelante a los posteriores en que resulte aplicable. [...]

De esta manera, con la referencia a los efectos retrospectivos se estará apuntando al hecho de que el cambio de precedente debe tener aplicación en el caso sub examine y en todos los otros que se encuentren bajo el mismo supuesto fáctico siempre y cuando no se trate de situaciones jurídicamente consolidadas, es decir, que no cuenten con un fallo judicial definitivo en firme o en los que ya haya ocurrido un perjuicio irremediable.

Efecto retroactivo: En el efecto retroactivo "el justiciable actúa inicialmente con base en una jurisprudencia anterior que, tiempo después, resulta modificada por una nueva orientación que tiene efectos retroactivos, es decir, cuando se le aplica posteriormente por el tribunal al resolver en definitiva la controversia" (Alvarado, 2012, pág. 36). Ejemplo de esto ocurrió con la sentencia SU-095 de 2018. El precedente judicial horizontal aplicable era la sentencia T-445 de 2016, y el Auto 053 de 2017, en tanto establecieron como subregla la competencia de las entidades territoriales para prohibir actividades extractivas, mediante consultas populares ambientales. Sin embargo, en la SU-095 de 2018 se sostuvo lo contrario, y se aplicó la nueva ratio decidendi regresiva a la consulta popular de Cumaral (Meta) que para la fecha ya había sido realizada (Benavidez, 2020). Es decir, hubo aplicación retroactiva inmediata a un caso que surgió en vigencia del precedente judicial anterior al recién creado por la Corte Constitucional.

De otro lado, Ricardo Ezqueda (2018) y Cuesta Simanca (2012) presentan algunos ejemplos reales de la aplicación retroactiva de los cambios jurisprudenciales en la jurisdicción de lo contencioso administrativo: En asuntos de la capacidad procesal de consorcios y uniones temporales; responsabilidad del Estado por enriquecimiento sin causa (actione in rem verso); privación injusta de la libertad; liquidación de perjuicios patrimoniales; requisitos de existencia o perfeccionamiento de los contratos estatales; contrato de realidad en contratos de prestación de servicios profesionales; carga de la prueba en responsabilidad médica; sanción moratoria, la posibilidad de renunciar tácitamente o no a la cláusula compromisoria en contratación estatal, etc. Para evidenciar aún más la veleidad jurisprudencial del órgano de cierre de lo contencioso administrativo (Ospina, 2014), se explica con más detalles este último ejemplo.

En un primer momento el Consejo de Estado sostuvo la tesis de la renuncia tácita de la cláusula compromisoria en vigencia del Decreto 1818 de 1998, antecesor de la Ley 1563

26 “Pero, más allá de estos condicionamientos, la Sala Especializada en Asuntos Electorales del Consejo de Estado destaca que cualquier tipo de modificación recaída sobre el derecho pretor debe ser expresa y debidamente motivada, a las voces del artículo 103 del CPACA, y la irradiación de sus efectos solo podrá producirse, por regla general, hacia el futuro, eso sí anticipando su aplicabilidad a través del instituto, denominado como el de la jurisprudencia anunciada, que matiza las consecuencias de las alteraciones interpretativas de las disposiciones constitucionales, legales y reglamentarias, comoquiera que propugna por una aplicación modulada en el tiempo -hacia el futuro - de las nuevas previsiones hermenéuticas". (Consejo de Estado. Sección Quinta. Sentencia del 18 de febrero de 2021. Radicación número: 11001-0328-000-2020-00058-00. C.P. Lucy Jeannette Bermúdez Bermúdez). 
de $2012^{27}$. Postura sustentada en el principio de autonomía de la voluntad. Si las partes habían acordado la cláusula compromisoria en el contrato estatal, y una de ellas declinaba demandando ante el juez administrativo, y la otra no proponía la excepción dentro de la oportunidad procesal correspondiente, entonces el asunto debía ser resuelto por el juez natural del contrato estatal. Sin embargo, el 18 de abril del 2013 la Sección Tercera profirió sentencia de unificación dentro del expediente Nro. 17.859, cambiando la subregla para la época vigente ${ }^{28}$, en el entendido de que sólo procedía la renuncia expresa del pacto compromisorio $^{29}$ (Chala, 2019).

Al margen de si este cambio jurisprudencial es legítimo o no (Ospina, 2014) (López Medina, 2017), lo cuestionable es que el Consejo de Estado aplicó retroactivamente la nueva subregla a una demanda que fue interpuesta el 4 de agosto de 1998, respecto de un contrato de obra pública celebrado el 25 de junio de 1996. A causa de la congestión judicial, tuvieron que pasar más de 14 años para que el Consejo de Estado decidiera la segunda instancia de este litigio. Pero al resolverlo creó una nueva regla ${ }^{30}$ que aplicó inmediatamente al caso analizado, sin respetar los derechos fundamentales de las partes a la igualdad, la seguridad jurídica, la buena fe, y la confianza legítima (Chala, 2019¹).

En la sentencia del 18 de abril de 2013, el Consejo de Estado afirmó que unificó jurisprudencia. Sin embargo, lo que en realidad hizo fue apartarse de una línea jurisprudencial pacífica en materia de renuncia tácita de la cláusula compromisoria en contratación estatal $^{32}$. Este cambio jurisprudencial abrupto originó el salvamento de voto conjunto de los consejeros Stella Conto Díaz Del Castillo y Danilo Rojas Betancourth, quienes lo señalaron de "voluntarismo que raya en la arbitrariedad". Uno de los reparos de los dos magistrados disidentes concierne a la aplicación en el tiempo del cambio jurisprudencial. Según ellos es cuestionable desde todo punto de vista el efecto retroactivo que se le asignó al viraje ${ }^{33}$.

27 Chala (2019) cita como precedentes judiciales las siguientes providencias: Sección Tercera, sentencia del 19 de marzo de 1998, expediente 14.097; Sección Tercera, sentencia del 26 de febrero de 2004, expediente 25.094; Sección Tercera, sentencia del 16 de abril de 2005, expediente 25.934; Sección Tercera, sentencia del 19 de julio de 2006, expediente 20.189; Sección Tercera, sentencia del 22 de mayo de 2009, expediente 29.699; Sección Tercera, sentencia del 23 de junio de 2010, expediente 18.395 .

28 Sección Tercera, sentencia del 16 de marzo de 2005, expediente 27.934.

29 “El asunto súb judice resulta de especial importancia jurídica y, por lo tanto, su estudio debe realizarse en la Sala Plena de la Sección Tercera de esta Corporación, en la medida en que esta providencia pretende modificar la tesis jurisprudencial hasta ahora imperante, en relación con la renuncia tácita de la cláusula compromisoria solemnemente pactada entre las partes de un contrato estatal" (Sección Tercera, sentencia del 18 de abril del 2013, expediente Nro. 17.859).

30 “Pues bien, así como las partes deciden, de común acuerdo, someter sus diferencias al conocimiento de la justicia arbitral, empleando para ello la celebración de un pacto cuyas principales características son que sea expreso y solemne, de la misma manera aquéllas deben observar de consuno tales condiciones (forma expresa y solmene) si su voluntad es deshacerlo o dejarlo sin efectos, de suerte que, si optan libremente por la justicia arbitral y no proceden

como acaba de indicarse para cambiar lo previamente convenido, no tienen la posibilidad de escoger entre acudir a ésta o a los jueces institucionales del Estado, teniendo en cuenta que su voluntad inequívoca fue someterse a la decisión de árbitros" (Sección Tercera, sentencia del 18 de abril del 2013, expediente Nro. 17.859).

31 "Conforme con todo lo anterior, es claro que modificar un criterio, que además era pacífico en el Consejo de Estado, bajo el pretexto de unificar jurisprudencia, con efectos retroactivos, implica sorprender a las partes que actuaron conforme con los precedentes vigentes, y que en esa medida decidieron renunciar tácitamente la cláusula compromisoria, de modo que contrario a la finalidad del recurso que se ejerció, cual es la de unificar criterios jurisdiccionales para mantener claridad en el ordenamiento, se promulga la inseguridad jurídica.

Además, si como se dijo, la seguridad jurídica implica no sorprender a los particulares con actuaciones que aisladamente tengan fundamento jurídico pero que, al compararlas, resulten contradictorias, es claro que se consagra la prohibición de la renuncia tácita y su contradicción con el ordenamiento jurídico colombiano, por los motivos expuestos durante todo el texto.

De esta manera, la proscripción de la renuncia tácita afecta la seguridad jurídica por su contradicción con el ordenamiento jurídico y por su aplicación retroactiva" (Chala, 2019, pág. 28).

32"1. UNIFICAR LA JURISPRUDENCIA de la Sección Tercera de la Sala de lo Contencioso Administrativo del Consejo de Estado acerca de los requisitos formales que deben observarse para modificar o dejar sin efecto un pacto compromisorio (cláusula compromisoria o compromiso) celebrado por las partes de un contrato estatal, en los términos señalados en la parte motiva de la presente providencia". (Sección Tercera, sentencia del 18 de abril del 2013, expediente Nro. 17.859).

33 “En el sub lite, durante la actuación surtida en la primera instancia se les garantizó a las partes el trato igualitario dispensado por la jurisprudencia al acceso a la justicia de quienes, habiendo suscrito cláusula compromisoria, optan por 
Si bien el Consejo de Estado "unificó jurisprudencia" sobre la exigencia de la renuncia expresa de la cláusula compromisoria en contratación estatal, no moduló expresamente cómo debía aplicarse esta nueva subregla a todos aquellos procesos que estaban a despacho para sentencia de segunda instancia, y que habían nacido en vigencia de la subregla anterior (renuncia tácita). Frente a tal vacío las siguientes salas de decisión optaron por aplicar efectos prospectivos, retrospectivos, e incluso retroactivos (Serrato, 2019), mostrando que no hay uniformidad sobre el particular.

\section{Conclusiones}

Vía construcción jurisprudencial de la Corte Constitucional, y más recientemente de las otras altas cortes, desde finales del siglo XX Colombia viene implementando un sistema relativo de precedentes judiciales, tanto verticales como horizontales, considerándolos con fuerza vinculante para todos los jueces de la República (Quinche, 2020) (López Medina, 2018) (Ospina, 2014). Esta reconfiguración del sistema de fuentes se ha profundizado con la positivización del deber de obediencia a los precedentes judiciales (artículo 10, Ley 1437 de 2011; artículo 7, Ley 1564 de 2012). Concretamente mediante las sentencias de unificación del Consejo de Estado, y su mecanismo de extensión a terceros, tanto en sede administrativa como jurisdiccional (102, 269, 270, y 271 de la Ley 1437 de 2011). Figura que tiene ciertos rasgos semejantes con las sentencias de unificación de tutela de la Corte Constitucional (artículo 34 del Decreto Ley 2591 de 1991, artículo 61 del Acuerdo 02 de 2015).

Debido a la fuerza vinculante del precedente judicial, si el juez va a apartarse de este debe cumplir con la carga de la transparencia y la carga de la argumentación. Si no lo hace incurre en una causal de procedibilidad de acción de tutela contra providencias, o nulidad de sentencias de la Corte Constitucional, según sea el caso.

López Medina (2018) afirma que una de las causas del apartamiento del precedente es el cambio jurisprudencial, entendido como la creación de una nueva subregla frente a los hechos de un caso similar que previamente había sido resuelto en otro sentido, sin que hubiese cambiado la disposición a aplicar ni el contexto social (Cuesta Simanca, 2012).

En el evento de concluir que el cambio jurisprudencial es legítimo, surge la necesidad de determinar razonablemente la modulación de sus efectos en el tiempo, tanto para el caso analizado como para todos aquellos que están a despacho para sentencia en el mismo tribunal o en otros. Es decir, ¿cómo se va a aplicar la nueva subregla? En este escrito se explicó que la aplicación de los cambios jurisprudenciales puede ser ex nunc (efecto prospectivo), ex tunc (efecto retroactivo), o intermedio (efecto retrospectivo). A la luz de los ejemplos referenciados se demostró que, en ocasiones el Consejo de Estado ha prohijado el efecto prospectivo o de jurisprudencia anunciada, como en la sentencia de unificación del 27 de junio de 2017 (expediente 33.94534), o en el caso de la sentencia que resolvió la

dejarla al margen y acudir a la jurisdicción estatal con fundamento en el mutuo disenso tácito o expreso en todo caso concluyente, habiéndole generado la expectativa legítima de que con fundamento en una línea jurisprudencial pacíficamente acogida y con sustento normativo suficiente obtendrían de esta jurisdicción la resolución del conflicto, mediante una decisión motivada razonable y fundada en el sistema de fuentes.

Desde luego que los derechos a la igualdad y a la confianza legítima no pueden constituirse en límites que petrifiquen la jurisprudencia; lo que resulta cuestionable es que se sorprenda a los usuarios del servicio de justicia con cambios inopinados e injustificados sin darles la oportunidad de adaptarse a los nuevos criterios jurisprudenciales o, peor aún, su aplicación con efectos retroactivos.

Empero, para la posición mayoritaria nada de eso contó. Aplicando con efectos retroactivos el abrupto cambio jurisprudencial contenido en la decisión de la que disentimos, dejó sin efectos el trato igualitario y las expectativas legítimas frente a la línea jurisprudencial consolidada, desde antes de la presentación de la demanda, protegidas a lo largo de la actuación surtida en este proceso hasta el trámite del recurso de apelación de la sentencia que decidió el asunto en la primera instancia, haciendo caso omiso de los derechos a la igualdad y a la confianza legítima que le asisten a las partes". (Salvamento de voto conjunto de los magistrados Stella Conto Díaz Del Castillo y Danilo Rojas Betancourth respecto de la sentencia del 18 de abril del 2013, expediente Nro. 17.859).

34 "Ahora bien, comoquiera que esta sentencia de unificación comporta una modificación jurisprudencial que tendría efectos en la tasación y liquidación de nuevos perjuicios frente a los cuales no operó el principio de contradicción, la Sala empleará la figura de la jurisprudencia anunciada y, por tal motivo, esta alteración del precedente solo será aplicable 
demanda de nulidad electoral contra el fiscal Francisco Barbosa Delgado ${ }^{35}$, entre otros. Con el efecto prospectivo se respetan los derechos de las partes.

Sin embargo, en otros casos el Consejo de Estado ha cambiado su jurisprudencia de forma retroactiva, como ocurrió en materia de la renuncia expresa de la cláusula compromisoria en contratación estatal (sentencia de unificación de la Sección Tercera del 18 de abril del 2013, expediente Nro. 17.859), la capacidad procesal de consorcios y uniones temporales; la responsabilidad del Estado por enriquecimiento sin causa (actione in rem verso); privación injusta de la libertad; liquidación de perjuicios patrimoniales; requisitos de existencia o perfeccionamiento de los contratos estatales; contrato de realidad en contratos de prestación de servicios profesionales; carga de la prueba en responsabilidad médica; sanción moratoria, etc. (Ricardo Ezqueda, 2018) y (Cuesta Simanca, 2012). Al igual que lo hizo la Corte Constitucional en la sentencia SU-095 de 2018, con ocasión de las consultas populares ambientales.

Por último, los ejemplos expuestos evidencian que en Colombia urge pensar con profundidad la modulación razonable de los efectos temporales no solo de las sentencias de unificación de la Corte Constitucional, sino también del Consejo de Estado, pero a partir de un enfoque de derechos a la igualdad, la seguridad jurídica, la buena fe y la confianza legítima.

a los procesos que se inicien con posterioridad a esta providencia, en aras de garantizar los principios constitucionales al debido proceso y a la defensa de las entidades y sujetos demandados ante esta jurisdicción. Por tal motivo, la Sala no estudiará de fondo el reconocimiento de daños derivados a bienes convencional y constitucionalmente protegidos en el sub examine".

35 Consejo de Estado. Sección Quinta. Sentencia del 18 de febrero de 2021. Radicación número: 11001-03-28-0002020-00058-00. C.P. Lucy Jeannette Bermúdez Bermúdez 


\section{Bibliografía}

Alvarado, M. (2012). ¿Se acabaron los efectos retroactivos de la jurisprudencia? En: Revista del Instituto de la Judicatura Federal. N. ${ }^{\circ} 34$. México. Disponible en: https://www.ijf.cjf. gob.mx/publicaciones/revista/34/alvarado. pdf

Armenta Maestre K. V. (2014). Modulación de los efectos temporales de las providencias de unificación del Consejo de Estado en Colombia. Diálogos de Derecho y Política, (13), 47-70. Recuperado a partir de https://revistas.udea.edu.co/index.php/derypol/article/ view/19903

Barrero, J. A. (2018). Jurisprudencia constitucional. Precedentes de la humanidad. Casos y materiales. Bogotá: Legis.

Benavidez, C. (2020). Consultas populares ambientales y activismo judicial en Colombia: a propósito de la sentencia SU-095 de 2018. (Tesis de pregrado). Medellín: Universidad de Antioquia.

Bravo Restrepo, L. A. (2000). Legitimidad del control constitucional y los controles a la Corte Constitucional. Revista Estudios de Derecho de la Facultad de Derecho y Ciencias Políticas de la Universidad de Antioquia, 59(133-4), 73-95. Recuperado de https://aprendeenlinea.udea.edu.co/revistas/index.php/red/issue/view/3012

Chala, J. D. (2019). La renuncia de la cláusula compromisoria en los contratos públicos: un debate inconcluso. En UNA Revista de Derecho, Vol. 4: 2019. Recuperado de https:// una.uniandes.edu.co/images/Volumen4/Chala-para-publicar.pdf

Consejo de Estado. Sala de lo Contencioso Administrativo, Sección Tercera. Sentencia del 30 de marzo de 2006. Radicación No.: 25000-23-26-000-1999-01968-01(25662), Consejero Ponente Ramiro Saavedra Becerra.

Contreras Calderón, J. A. (2011). El precedente judicial en Colombia: Un análisis desde la teoría del derecho. Revista Facultad de Derecho y Ciencias Políticas. Vol. 41, No. 115, 331-361.

Corte Constitucional, Sentencia T-292 de 2006. M.P: José Manuel Cepeda. Bogotá D.C., seis (6) de abril de dos mil seis (2006).

Corte Constitucional. Sentencia C-539 de 2011. M.P: Luis Ernesto Vargas Silva. Bogotá, D.C., seis (6) de julio de dos mil once (2011).

Corte Constitucional. Sentencia C-816 de 2011. M.P: Mauricio González Cuervo, Bogotá D.C., noviembre 1 de dos mil once 2011.

Cuesta Simanca, A. (2012). Responsabilidad del Estado por aplicación retroactiva de cambios de jurisprudencia. Bogotá: Grupo Editorial Ibañez.

Cuesta Davu, A. A. (2016). Responsabilidad del Estado por simple cambio de jurisprudencia en el derecho colombiano. Revista Ratio Juris, 11(23), 47-71. Recuperado de https:// publicaciones.unaula.edu.co/index.php/ratiojuris/article/view/86

Deik, C. (2018). El precedente contencioso administrativo. Teoría local para determinar y aplicar de manera racional los precedentes de unificación del Consejo de Estado. Bogotá: Universidad Externado de Colombia. 
García López, E. (2011). La crisis de las fuentes del derecho. En J. González, \& E. García, La crisis de las fuentes del derecho en la globalización. Medellín: Biblioteca jurídica Dike.

López Medina, D. E. (2009). El derecho de los jueces. Bogotá: Legis.

López Medina, D. E. (2017). Eslabones del derecho. El deber de coherencia con el precedente judicial. Bogotá: Universidad de los Andes y Legis.

Linares, A. (2017). Prólogo. En Díaz, A. Sentencias de unificación jurisprudencial y mecanismos de extensión. Aplicación en materia tributaria. Bogotá: Universidad del Rosario y Legis.

Olano García, H. A. (2004). Tipología de nuestras sentencias constitucionales. Vniversitas, 53(108), 571-602. Recuperado a partir de https://revistas.javeriana.edu.co/index.php/ vnijuri/article/view/14750

Ospina Garzón, A. F. (2014). Los cambios de jurisprudencia en la jurisdicción de lo contencioso administrativo: ¿veleidad o independencia del juez? En Benavides, J. L. (Compilador). Contribuciones para el sistema de precedentes jurisprudencial y administrativo (pp. 21-58). Bogotá: Universidad Externado de Colombia.

Quinche, M. F. (2020). El precedente judicial y sus reglas. Bogotá: Legis.

Ricardo Ezqueda, R. (2018). Aplicación retroactiva y retrospectiva del precedente judicial según el Consejo de Estado colombiano. Revista del Instituto Colombiano de Derecho Procesal. No. 47, Enero-junio, pp. 193-218.

Santofimio Gamboa, J. O. (2010). La fuerza de los precedentes administrativos en el sistema jurídico del derecho positivo colombiano. Bogotá: Universidad Externado de Colombia.

Serna Mesa, J. A. (Mayo - Agosto de 2010). Bloque de constitucionalidad como fuente del derecho administrativo. Diálogos de Derecho y Política (4), 1-32.

Serrato, L. N. (2019). Aplicación en el tiempo del cambio de precedente judicial en las tres altas cortes: dinámica actual y propuesta de solución. (Tesis de grado). Bogotá: Universidad Externado de Colombia.

Tamayo, J. (2011). La decisión judicial. Análisis de la jurisprudencia de la Corte Constitucional. Bogotá: Biblioteca Jurídica Diké.

Taruffo, M. (2007). Precedente y jurisprudencia. Precedente. Revista Jurídica, 86-99. https:// doi.org/10.18046/prec.v0.1434

Uprimny, R., Fuentes, A., Botero, C., Jaramillo, J. F. (2006). Libertad de prensa y derechos fundamentales. Análisis de la jurisprudencia constitucional en Colombia (1992-2005). Bogotá: Fundación Konrad Adenauer, DEJUSTICIA, ANDIARIOS.

Wróblewski, J. (1985). Constitución y teoría de la interpretación jurídica. Madrid: Civitas. 